\title{
The Cognitive Foundations of Partitioned Country-of-Origin: A Causal Path Analysis
}

\author{
Md. Humayun Kabir Chowdhury \\ Department of Business Administration, East West University \\ 43 Mohakhali C/A, Dhaka 1212, Bangladesh \\ E-mail: mhkchowdhury@yahoo.com
}

\begin{abstract}
This paper proposes a framework for the analysis of partitioned country-of-origin associations on consumer product quality evaluations. This research clarifies the roles of country-of-design, country-of-assembly, country-of-parts and brand image in evaluating consumer perceptions of product quality. Data were analyzed via structural equation models using Amos 5.0. Results from structural equations analysis reveal a broader conceptualization of consumer perceived quality in Bangladesh as reflected in the model. In particular it was found that for high involvement products like television, perceived country-of-origin association instead of brand image significantly influence in shaping perceptions of quality in the country.
\end{abstract}

Keywords: Country of design, Consumer brand image, Country of assembly, Perceived product design, Country of parts, Perceived product sophistication, Perceived product quality, Perceived manufacturing excellence

\section{INTRODUCTION}

Country-of-origin is widely accepted as the overall perception consumers' form of products from a particular country, based on their prior perceptions of the country's production and marketing strengths and weaknesses (Roth and Romeo 1992). Moreover, studies suggest country-of-origin has a positive effect on consumers' perceptions of product quality (Bannister and Saunders 1978; Erdem et al. 2006; Johansson 1989; Kapferer 1994; Jo 2005; Nagashima 1970). That is, consumers are willing to pay premium prices for a product made in a specific country such as Japanese mechanizes, French perfumes, Italian fashions, and so on. The literature on country-of-origin effects has been enriched with a wide range of different premises and experiments from different countries. The majority of these studies demonstrate the existence of country-of-origin effects on product evaluation, although the magnitude, direction and process vary considerably (Elliott and Cameron 1994; Iyer and Kalita 1997; Maheswaran 1994; Okechuku 1994).

A few recent $\mathrm{COO}$ studies have addressed these research issues but they have been conducted in highly industrialized countries (Ahmed, d'Astous, and Mathieu 1995; Insch and McBride 1998). Very few studies have tried to find out if COO effects exist for consumers in the developing countries (Ahmed and d'Astous 1999). But, consumer markets in the west are saturated. The growth of consumer markets in the coming years will occur mostly in developing countries in Asia and South America (Bandyopadhyay and Banerjee 2002). In order to generalize research findings to the global context, COO studies must be conducted in the developing countries. Furthermore, research has shown that country image perceptions may vary depending on the level of economic development of the country (Papadopoulos, Heslop and Bamossy 1998). In many developing countries, especially those with a low per capita income, inefficient marketing systems prevail. Large differences in market structures and consumer behavior between developed and developing countries are therefore prevalent and COO results obtained in developed countries may not necessarily apply to developing countries (Ahmed and d'Astous 1999). Therefore, to investigate the effects of partitioned COO on product quality perceptions in the developing country perspective is another important question to answer.

Understanding consumers' opinion toward products from various countries can be useful in developing multinational strategic marketing policies. If country-of-origin is to be used as a competitive tool, managers must also understand the mechanism of country-of-origin on consumer quality perceptions. Research on evaluation of foreign products infers that the producing country affects consumers' judgments of product quality (Bilkey and Nes 1982; Hong and Wyer 1989). For example, a country's image regarding workmanship and technological advancement logically will be projected onto the features of products produced by that country. Product quality evaluation is conceptualized as the attitudes consumers hold towards their targeted products.

In the last twenty years, companies have grown globally by delocalizing part of their manufacturing operations. As a result of the expansion of multinational firms, companies sell the same products under identical brand names in different countries throughout the world. Studies found that, in presence of established brands, the 
$\mathrm{COO}$ of a product may not be an important consideration. These studies found $\mathrm{COO}$ to exert either no impact at all or only a very weak impact on consumer product evaluation (Johansson, Douglas, and Nonaka 1985). Other studies, however, have found significant COO effects on consumers' evaluation of foreign products (Elliott and Cameron 1994; Ahmed and d'Astous 1996; Iyer and Kalita 1997). Han and Terpstra (1988, p. 244) sought to determine which of the two effects had more influence, and their conclusion was that: "the sourcing country has greater effects on consumer evaluations of product quality than does the brand name". However, Eroglu and Machleit (1989) concluded that consumers accord a similar influence to brand and country of manufacture respectively. Ahmed et al. (1995), in the case of industrial products, show that country of design is a more important cue in organizational purchase decisions than brand name. What underlies the differences in these research findings? Johansson (1989) acknowledged this inconsistency and proposed that the information value of COO may depend upon the availability of other cues. In an era where global brands are aggressively marketed, would $\mathrm{COO}$ lose its information value? Alternatively, the effect of $\mathrm{COO}$ may have become more complicated in the era of globalization.

This study is designed to assess the salience of $\mathrm{COO}$ associations in presence of brand name. A brand name is created by a firm through its marketing effort. The marketing literature has long established the importance of brand names in product evaluation, and it is generally accepted that consumers often use brand names as surrogates for product quality, especially when other cues are not available. The relative impact of COO associations and brand name in consumer product evaluation is important and has managerial implications. If $\mathrm{COO}$ is salient relative to brand name, there may be opportunities for a marketer to adopt a strategy by producing new products in countries which have favorable image. If $\mathrm{COO}$ is no longer important compared to brand name, a marketer may want to produce and market his/her own brands instead of continuing to produce for firms with established brands.

\section{OBJECTIVE OF THE RESEARCH}

In spite of the vast number of empirical country-of-origin studies, little is known about the psychological structure of the effects of a product's country-of-origin on quality perceptions toward a product. Therefore, the main purpose of this research is to examine the influence of various types of cognitive evaluations that consumers in a developing country might use to assess the offerings when they assess quality. The literature on country-of-origin associations and brand image is integrated here to provide a sound conceptual foundation for investigating factors important in consumer quality judgment formation. Thus, the study has two primary objectives.

The first objective is to develop a better understanding of the country-of-origin effect by separately examining the effects of the country-of-design (COD), the country-of-assembly (COA), and the country-of-parts (COP) of a product. More specifically, the objective is to address the effects of these constructs in presence of brand name (BI). In most studies, all four constructs have not been included simultaneously. Thus, an examination of the specific associations of these constructs (i.e., $\mathrm{COD}, \mathrm{COA}, \mathrm{COP}$ and $\mathrm{BI}$ ) to consumer perceived quality judgment is of primary interest of this study. The second objective is to discuss the implications of the findings for domestic and global marketing managers.

\section{CONCEPTUAL FRAMEWORK AND MODEL SUMMARY}

Partitioned COO differs in their focus from product context. The former deal broadly with the country, whereas the latter deal with a specific product. Previous studies have confounded country image with product image. Product image is consumers' overall perceptions of the products from a particular country, and it has three aspects: design, sophistication, and manufacturing excellence. Therefore, we agree with the current thinking in the literature that suggests that the country and the products it offers are separate entities (Mort and Duncan 2003). The distinction between country image and product image raises the following question: what is the relationship between the two image constructs? Answer to this question can shed additional light on how COO effects operate. The degree to which country and product associations influence each other is an open question for which little empirical evidence exists.

There are three types of studies on COO: (1) studies dealing consumers' perceptions about various countries; (2) studies examining the impact of country image on consumers' product evaluations and purchases; and, (3) studies investigating partitioned $\mathrm{COO}$ on consumers' product evaluations. Studies on $\mathrm{COO}$ perceptions have consistently demonstrated that consumers hold different perceptions about various countries. However, the results of studies on the impact of $\mathrm{COO}$ have been mixed. One of the reasons for the mixed results could be that $\mathrm{COO}$ image has been confounded with the image of products made in a country. The inconsistent results in the literature leave marketing managers with the intuitive implication that a good image is probably better than a bad 
image, but with little else to guide them as to how particular country positioning strategies might influence consumer product responses. We believe that one of the reasons for the inconsistency of prior results is that not all country association (multinational) designs are alike. Two countries of design may have the same overall degree of favorability for consumers, yet each country might experience difference influences of country associations on consumer product responses. We believe that to understand these different effects it is important to distinguish country associations (COD, COA, and COP) and should ascertain their influences on product associations and consumers' behavioral intentions.

We summarize the ideas presented in the model illustrated in Figure 1. On the basis of our discussion, we predict that country association together with brand image influence the perception of product associations (PPD, PPS, and PME). The basic assumption is analogous to the previous information processing studies (Olson 1977; Olson and Jacoby 1972). In general, it is believed that consumers consider extrinsic cues such as country information and brand name as product quality indicators, and use them more often when intrinsic attributes are not available. However, since most COO studies have taken a single-cue approach, it is still unclear how these cues would interact with each other under various conditions.

Consider a case where consumers are trying to evaluate a multinational product without any specific attribute/feature information - a Sony TV - obviously designed in Japan, assembled in Malaysia, and the parts are produced in China, for instance. In this case, the brand name, Sony, and the country associations are associated with different sets of knowledge and affective reactions. The information integration literature suggests that under this type of situation, consumers use some type of integration rule that would combine their affective reactions to each piece of information into the final evaluation of the product (Lynch 1985).

The hypothetical model (Figure 1) consists of the eight latent constructs and the expected relationships among them. Based on the theory of consumer information processing (Bettman 1979; Bettman, Luce, and Payne 1998), attitude theory (Ajzen and Fishbein 1980) and findings in the area of country-of-origin research (Han 1989; Han and Terpstra 1988; Insch and McBride 1998), a set of hypothesized relationships among the constructs were determined. Four of the eight constructs of the model, COD, COA, COP, and CBI are exogenous variables. All other latent variables are endogenous. Each construct is connected to three to four observable indicators which serve as measures. Measurement issues, such as the selection of indicators and their treatment within the measurement models, are discussed in more detail in the methodology and results sections.

Based on the assumption that the more general constructs affect the more specific product related ones, the direction of the hypothesized effects is from the evaluation of the country to the evaluation of the country's products and to the attitude and intention of products made in the country.

This model is important because it allows for the possibility of multiple paths of influence for country associations on consumer product responses, a component missing from prior studies of $\mathrm{COO}$ reported in the literature. In addition it recognizes an important distinction between different types of country associations and their influences on different product context.

\section{RESEARCH METHODOLOGY}

\section{Data Collection Procedure}

A questionnaire served as the data-gathering instrument. Because of subjects' relative unfamiliarity with the brands, description information about COD, COA, and COP was provided as part of the manipulation of independent variables (see Appendix A). Because of the limited knowledge about the influence of country associations available in the literature, our research strategy has begun with a test of the effects under conditions that has attempted to control for potential threats to internal validity. Three countries have been chosen: Japan, China, and Bangladesh to test the influence of COD, COA, and COP. The questionnaire was developed in English and translated into Bengali as the data has been collected in Bangladesh. A student sample has been used in this study. The design of the questionnaire has been developed in this study to estimate the impact of COD, $\mathrm{COA}$, and $\mathrm{COP}$ on product context and the product quality evaluations.

\section{Measurement of the Variables}

Current study dealt with eight constructs and their observed measures. The questionnaire contained multiple measures of all eight latent variables of the model. The selection of these indicators was based on an extensive literature review. All measures used in the present study had already been used and found to be valid and reliable indicators in one or more previous studies. The main sources used in this selection process were: Insch and McBride (1998), Parameswaran and Yaprak (1987), Bandyopadhyay and Banerjee (2002), Ahmed and d'Astous (1999), Han and Terpstra (1988). For all these directly observed variables, ratings were obtained on a 
seven-point scale ranging from 7 = "Strongly Agree" to 1 = "Strongly Disagree".

In this questionnaire consumers were given specific brand name information in addition to COD, COA, and COP. For example, a description for COD such as "Japan has designed a television -----" has been changed into "China/Bangladesh has designed a television ---". Similarly, the description for COA is - "China assembled the final product-----" has been changed into - "Japan/Bangladesh assembled the final product----". Finally, the description for COP is - "Major parts have been produced in Bangladesh" has been changed into - "Major parts have been produced in Japan/China". Three item scales used to measure brand image were: (a) Rangs will produce good quality television; (b) Consumers will like television produced by Rangs; and, (c) Television produced by Rangs will be superior to any other. The brand name was put together such that they varied in terms of favorableness and relevance to the evaluation task. Table 1 shows the procedure for developing the questionnaire.

\section{RESULTS}

\section{Overall Model Fit:}

The first step of the data analysis was to assess the measurement model. The objectives of this test were: (1) to assess the validity and reliability of the measures used and (2) to select the best subset of observed measure for use in testing the structural model. The data approximated a normal distribution with acceptable skewness and kurtosis values. We used factor analysis with varimax rotation to produce the measures for all the measures of factors used in the path analysis. Coefficient alpha was computed first for each set of observed measures associated with a given latent variable (see Table 2).

Bagozzi and Yi (1988) have pointed out that "one of the first things that should be done before examination of the global criteria is to see if any anomalies exist in the output (p.76)." Such anomalies might include: (1) negative estimates for the variances, (2) correlation estimates greater than 1, and (3) extremely large estimates for the parameters. None of these anomalies resulted from the analysis. The results of the structural analysis appear in Figure 2.

The results of this study provide important confirmation that country associations can influence consumer responses to products introduced by country. Table 3 presents the factors that have been considered in this study and their corresponding hypotheses. The linkages between the factors have been considered as the hypotheses for testing the influences of the factors. The path coefficients have found to be significant. Only one path (COA to PPS) is not in accordance with the directions proposed in the model. This means that in evaluation of perceived product sophistication (PPS), COA does not have any significant influence.

\section{DISCUSSION}

The results of the structural analysis provided a basis for making inferences about the theoretical relationships among the selected constructs where both partitioned COO (COD, COA, and COP) and partitioned COO together with brand image (BI) cues were combined in the same research setting. Based on a simple model of the linkages between the constructs, the overall research results fit the conceptual model rather well, indicating that all the cues affect consumer perceptions of quality although the magnitude of their influence varies. Consequently, the findings of this study may serve as a useful tool in future research on consumer country-of-origin in other settings. By understanding the role of the cues in influencing quality judgments for the consumers in a developing country, this information could be vital in marketing strategy formulation, strategic planning and perhaps even foreign direct investment decisions.

Although country-of-origin influence has a long history in marketing, we found limited empirical evidence in the literature on the relationship between partitioned country-of-origin associations and product level responses. Therefore, our goal was to begin to systematically explore the influence of partitioned country-of-origin associations on consumer product quality evaluations. We also sought to differentiate among three distinct types of country-of-origin associations - $\mathrm{COD}, \mathrm{COA}$, and $\mathrm{COP}$ - and investigate the nature of the influence that each might have on product quality evaluations.

In many situations, important product attributes cannot be fully evaluated prior to purchase, information is effectively missing about these attributes. The results of all three studies indicate that consumers can and will use country-of-origin associations as the basis for inferences about missing product attributes. Thus, through the development of country-of-origin associations, marketing managers can leverage what consumers know about a company to compensate for what they do not know and cannot evaluate about a product.

In addition, country-of-origin associations can influence product evaluations through their effect on how consumers feel about the country. The country-of-origin evaluation exhibited an influence on the product 
evaluation that was independent of the influence of country-of-origin associations on specific product evaluations. Thus, even in situations in which product attribute levels are known prior to purchase and consumption, a company may still derive value from the partitioned country-of-origin associations that consumers possess.

\section{CONCLUSION AND IMPLICATIONS}

At the theoretical level, this study provides greater understanding of the variables (i.e., partitioned COO and brand name) that appear to be most influential in structuring consumer perceptions of quality in Bangladesh. The model as a whole suggests that when a consumer evaluates the quality of a product, s/he may retrieve the constructs directly.

From a practical standpoint, this study should provide managers with greater insight concerning the potential benefits (and limitations) associated with using country-of-origin strategies in developing countries. This research clarifies the roles of COD, COA, COP, and brand image in evaluating product quality. Practitioners may use the finding to design marketing programs that create positive evaluations and avoid negative effects.

The country-of-origin effect has received considerable attention in international marketing research. Studies have found that $\mathrm{COO}$ information has stronger effects in less developed countries (Verlegh and Steenkamp 1997). Despite this general finding and a variety of studies conducted on the subject, most COO studies are of general nature (Leonidou et al. 1999).

Our study is done from the perspective of Bangladeshi consumers. This study has investigated two major issues: (1) it investigated the effects of COD, COA, and COP on judgment of product quality; and, (2) it explored the influences of price together with partitioned $\mathrm{COO}$ in consumer evaluations of product quality.

Therefore, this paper contains two primary contributions to the existing country-of-origin literature. First, an extended country-of-origin and perceived quality model is proposed with a third component, COP. This model was empirically tested and supported. Second, the model was decomposed into evaluation of country-of-origin associations, evaluation of the product, and evaluation of the quality which were empirically tested and also supported. The description of the model includes definitions of the essential constructs and a theorized relationship of the relative strength of each component of the country-of-origin construct on consumers' perceived product quality evaluations.

\section{LIMITATIONS AND DIRECTIONS FOR FUTURE RESEARCH}

Because this study represent preliminary forays into the effects of country associations, they possess several limitations. We suggest several promising avenues for further research that will enable marketers to gain a better understanding of the influence of country associations on consumers' product quality evaluations.

One of the shortcomings of this study is the use of convenient student samples. Consequently, the generizability of our results may be limited. In spite of evidence about student versus non-student samples (Peterson and Jolibert 1995), the prudent reader should take this potential limitation into account when interpreting our findings. On the other hand, student subjects are acceptable when tests of theory rather than effect size estimates are the goal. The current study's focus on theory testing may therefore mitigate this concern.

The study is carried out in Bangladesh. The results may not be directly applied to another country. However, a similar research methodology may be used to examine possible country-of-origin effects in other developing as well as developed countries.

Another important research extension could include longitudinal studies of the variables considered in this study. Bilkey (1993) asserted that countries can change their images (i.e., Japan and South Korea). More importantly, he noted that while it took Japan almost 20 years to substantially improve its image, South Korea has managed the same feat in half the time. Consequently, it appears that the time required for a country to change its image may be diminishing. Understanding the essential variables that affect this change would be a tremendous help for those developing countries that wish to change their national image.

The final area concerns country-of-origin effects on purchase intentions and actual purchases. For example, when do country-of-origin cues become the dominant reference point for consumers' intent to purchase and/or final purchase choice? Which of the three proposed components of country-of-origin is most closely aligned with purchase intentions?

\section{References}

Ahmed, Sadrudin A., Alain d'Astous and A. Mathieu. (1995). Influences relatives des lieux de conception et d'assemblage sur la perception des produits. Canadian Journal of Administrative Sciences, 12 (3), 210-223 
Ahmed, Sadrudin A., and Alain d'Astous. (1996). Country-of-Origin and Brand Effects: A Multi-Dimensional and Multi-Attribute Study. Journal of International Consumer Marketing, 9 (2), 93-115

Ahmed, Sadrudin A., and Alain d'Astous. (1999). Product-Country images in Canada and in the People's Republic of China. Journal of International Consumer Marketing, 11(1), 5-22

Bagozzi, Richard P., and Yi, Y. (1988). On the Evaluation of Structural Equation Models. Journal of the Academy of Marketing Science, 16, Spring, 74-94

Bandyopadhyay, Subir and Banerjee, Bibek. (2002). A Country-of-Origin Analysis of Foreign Products by Indian Consumers. Journal of International Consumer Marketing, 15 (2), 85-109

Bannister, J. P., and Saunders, J. A. (1978). UK Consumers Attitude towards Imports: The Measurement of National Stereotype Image. European Journal of Marketing, 12, 562-570

Bilkey, Warren J. (1993). Foreword," in Product Country Images: Impact and Role in International Marketing, eds. Nicolas Papadopoulos and Louise A. Heslop, New York: International Business Press, xix

Bilkey, Warren. J., and Erik Nes. (1982). Country-of-Origin Effects on Product Evaluations. Journal of International Business Studies, 13 (Spring/Summer), 89-99

Elliot, G. R., and Cameron, R. S. (1994). Consumer Perception Product Quality and the Country of Origin Effect. Journal of International Marketing, 2 (2), 49-62

Erdem, Tülin, Joffre Swait and Ana Valenzuela. (2006). Brands as Signals: A Cross-Country Validation Study. Journal of Marketing, 70 (1), 34-49

Eroglu, S.A., and K.A. Machleit. (1989). Effects of Individual and Product Specific Variables on Utilizing Country of Origin as a Product Quality Cue. International Marketing Review, Vol. 6 (6), 27-41

Han, C. M., and Terpstra V. (1988). Country-of-origin: Effects for Uni-national and Bi-national Products. Journal of International Business Studies, 16 (Summer), 235-256

Hong, S. T., and Wyer R. S. Jr. (1989). Effects of Country of Origin and Product Attribute Information on Product Evaluation: An Information Processing Perspective. Journal of Consumer Research, 16 (September), $175-187$

Insch, Gary S., and McBride, J. Brad. (1998). Decomposing the Country-of-Origin Construct: An Empirical Test of Country of Design, Country of Parts and Country of Assembly. Journal of International Consumer Marketing, 10 (4), 69-91

Iyer, G. R., and Kalita J. K. (1997). The Impact of Country of Origin and Country of Manufacture Cues on Consumer Perceptions of Quality and Value. Journal of Global Marketing, 11 (1), 7-28

Jo, Myung-Soo. (2005). Why Country of Origin Effects Vary in Consumers' Quality Evaluation: A Theoretical Explanation and Implications for Country of Origin Management. Journal of Global Marketing, 19 (1), 5-15

Johansson, J. K., and Nebenzahl, I. D. (1986). Multinational Production: Effect on Brand Value. Journal of International Business Studies, (Fall), 101-26

Johansson, J. K., Douglas, S. P., and Nonaka, I. (1985). Assessing the Imapact of Country of Origin on Product Evaluation: A New Methodological Perspective. Journal of Marketing Research, 22 (November), 388-396

Johansson, Johny K. (1989). Determinants and Effects of the Use of 'Made-in' Labels. International Marketing Review, 6(1), 47-58

Kapferer, Jean-Noel. (1994). Strategic Brand Management: New Approaches to Creating and Evaluating Brand Equity. New York: Free Press

Leonidou, L. S., Hadjimarcou, J., Kaleka, A., and Stamenova, G. T. (1999). Bulgarian consumers' perception of products made in Asia Pacific. International Marketing Review, Vol. 16 No. 2, pp. 126-142

Lynch, John G. Jr. (1985). Uniqueness Issues in the Decompositional Modeling of Multivariate Overall Evaluations: An Information Integration Perspective. Journal of Marketing Research, 22, 1-19

Maheswaran, Durairaj. (1994). Country of Origin as a Stereotype: Effects of Consumer Expertise and Attribute Strength on Product Evaluations. Journal of Consumer Research, 21 (September), 354-365

Mervis, Carolyn B., and Eleanor Rosch. (1981). Categorization of Natural Objects. Annual Review of Psychology, 32, 89-115

Mort, Gillian Sullivan and Duncan, Matthew. (2003). Owned by ...”: Country of Origin's New Cue. Journal of 
International Consumer Marketing, 15(3), 49-69

Nagashima, Akira. (1970). A Comparison of Japanese and U.S. Attitudes toward Foreign Products. Journal of Marketing, 34 (January), 68-74

Okechuku, C. (1994). The Importance of Product Country of Origin: A Conjoint Analysis of the United States, Canada, Germany, and the Netherlands. European Journal of Marketing, 18 (4), 5-19

Olson, Jerry C. (1977). "Price as an Information Cue: Effects on Product Evaluations," in Consumer and Industrial Buying Behavior, edited by Arch G. Woodside, Jagdish J. Sheth, and Peter Bennet. New York: North-Holland

Olson, Jerry C., and J. Jacoby. (1972). Cue Utilization in the Quality Perception Process. Proceedings of the $2^{\text {nd }}$ Annual Convention of the Association for Consumer Research, Chicago, IL: 167-79

Papadopoulos, N., and Heslop, L. A. and Bamossy, J. G. (1998). A Comparative Image analysis of Domestic versus Imported Products. International Journal of Research in Marketing, 7, 283-294

Peterson, Robert A., and Alain, J. P. Jolibert. (1995). A Meta-Analysis of Country-of-Origin Effects. Journal of International Business Studies, 26 (4), 883-900

Roth, Martin S., and Jean B. Romeo. (1992). Matching Product Category and Country Image Perceptions: A Framework for Managing Country of Origin Effects. Journal of International Business Studies, 23 (3), $477-497$

Verlegh, W. J., and Steenkamp, J. B. E. M. (1997). Country-of-origin effects: A meta-analytic review. Marketing: Progress, Prospects, Perspectives (D. Arnott et al., eds), Warwick Business School, pp. 2136-2140

Table 1. The Questionnaire Design

\begin{tabular}{|l|l|l|l|}
\hline \multicolumn{2}{|l|}{ Television } & COA & COP \\
\hline No. & COD & Japan & Japan \\
\hline 1. & Japan & China & China \\
2. & China & Bangladesh & Bangladesh \\
3. & Bangladesh & China & Bangladesh \\
4. & Japan & Japan & Bangladesh \\
5. & China & Japan & China \\
6. & Bangladesh & Bangladesh & China \\
7. & Japan & Bangladesh & Japan \\
8. & China & China & Japan \\
9. & Bangladesh & \multicolumn{2}{|l}{} \\
\hline
\end{tabular}

Table 2. Values of Coefficient Alpha

\begin{tabular}{|l|l|l|}
\hline Constructs in the Model & Items & Alpha Values \\
\hline & & \\
Perceived Product Quality (PPQ) & 3 & 0.84 \\
Perceived Product Design (PPD) & 2 & 0.80 \\
Perceived Product Sophistication (PPS) & 2 & 0.85 \\
Perceived Manufacturing Excellence (PME) & 2 & 0.85 \\
Country-of-Design (COD) & 3 & 0.91 \\
Country-of-Assembly COA) & 3 & 0.86 \\
Country-of-Parts (COP) & 3 & 0.96 \\
Consumer Brand Image (CBI) & 3 & 0.87 \\
\hline
\end{tabular}


Table 3. Structural Model Estimation Results (Standardized)

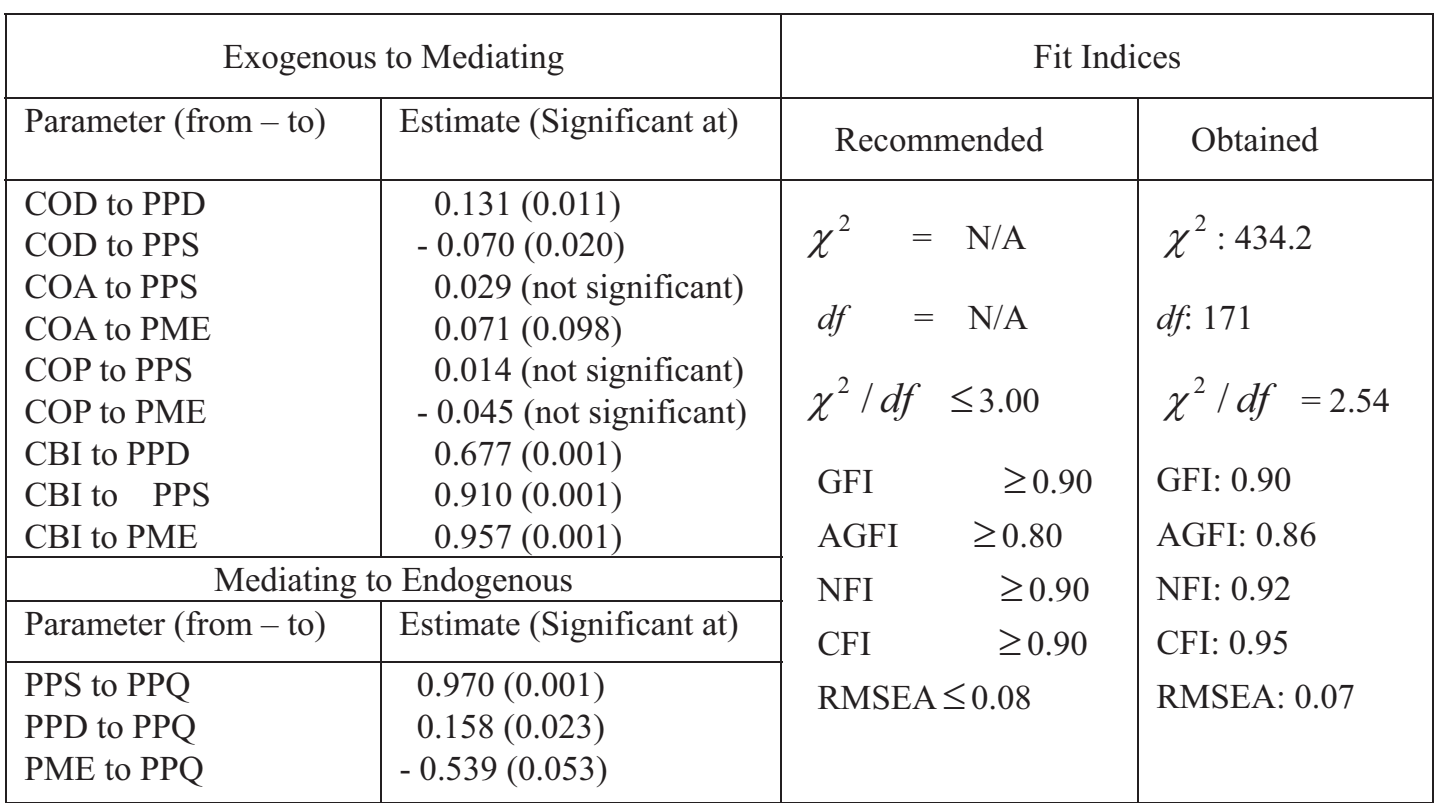

COD: Country of Design PPD: Perceived Product Design COA: Country of Assembly PPS:

Perceived Product Sophistication COP: Country of Parts PME: Perceived Manufacturing Excellence CBI: Consumer Brand Image PPQ: Perceived Product Quality

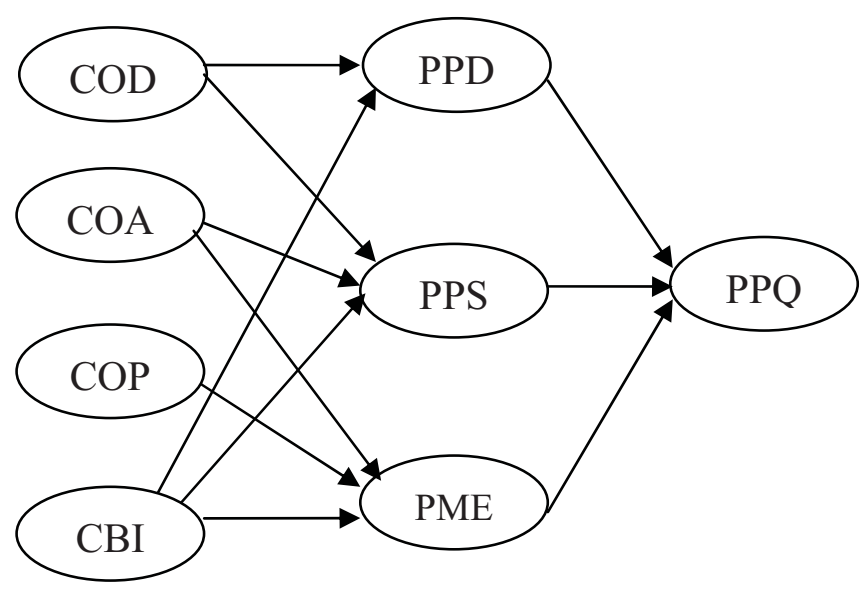

Abbreviation:

COD: Country of Design

COA: Country of Assembly

COP: Country of Parts
CBI: Consumer Brand Image PPD: Perceived Product Design

PPS: $\quad$ Perceived Product Sophistication

PPQ: Perceived Product Quality PME: Perceived Manufacturing Excellence

Figure 1. A Theoretical Model 


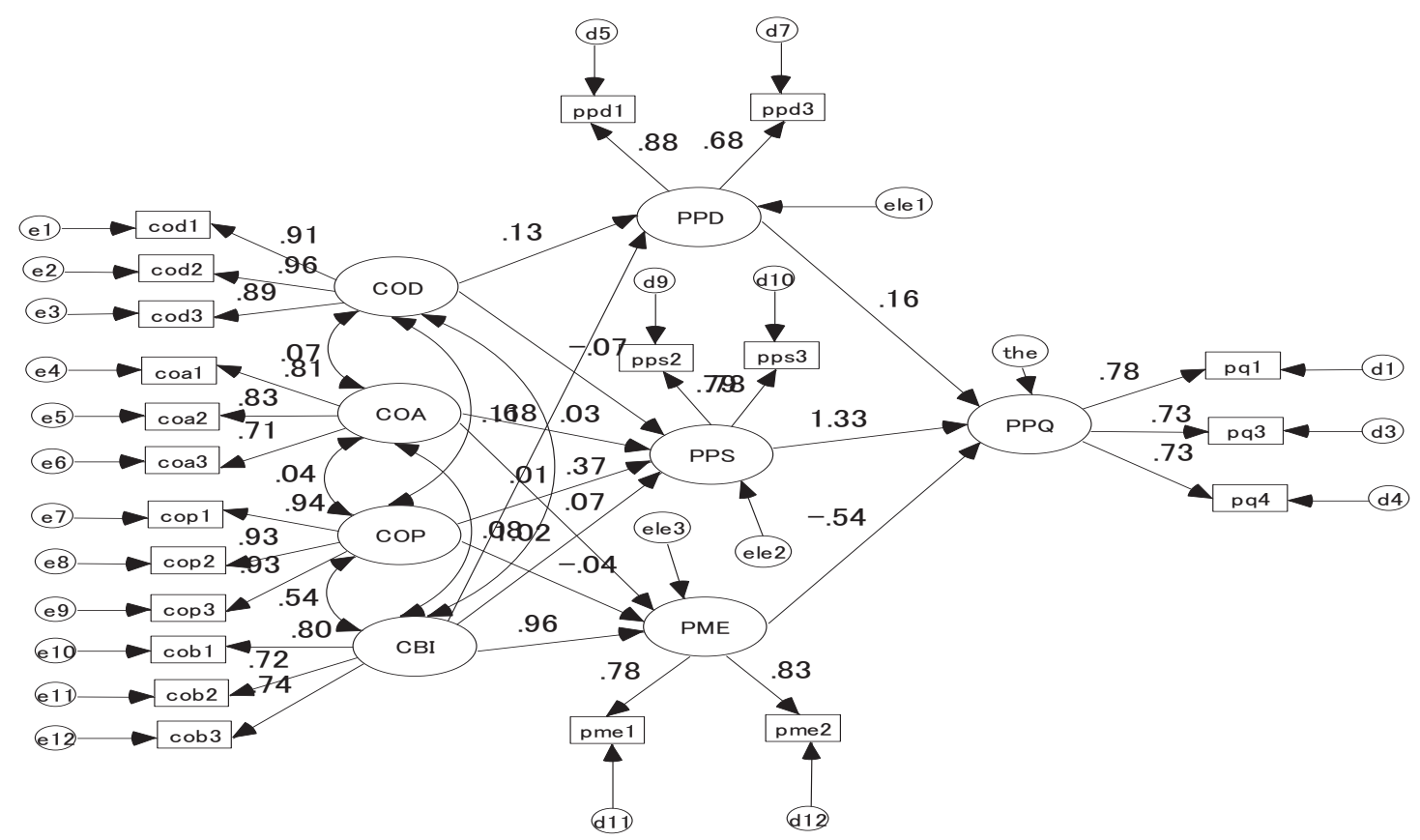

Abbreviations:

$\mathrm{PPQ}=$ Perceived Product Quality

PPS = Perceived Product Sophistication COD = Country of Design

PPD $=$ Perceived Product Design

PME = Perceived Manufacturing Excellence

COA = Country of Assembly

$\mathrm{CBI}=$ Consumer Brand Image

Figure 2. Influence of Country Associations and Brand Name on Product Evaluations 